\title{
ACUTE INTENTIONAL POISONINGS WITHIN AN URBAN AGGLOMERATION IN POLAND IN 2004-2013
}

\author{
ANNA PIEKARSKA-WIJATKOWSKA ${ }^{1}$, KATARZYNA KOBZA-SINDLEWSKA ${ }^{1}$, JOLANTA PRZYŁUSKA ${ }^{2}$, \\ and ANNA KRAKOWIAK ${ }^{3}$
}

Nofer Institute of Occupational Medicine, Łódź, Poland

${ }^{1}$ Toxicology Clinic, Poison Information Centre

${ }^{2}$ Department of Knowledge Management

${ }^{3}$ Toxicology Clinic, Department of Toxicology

\begin{abstract}
Objectives: The aim of the research was to analyze the nature of changes and tendencies observed in the frequency, circumstances and causes of acute intentional poisonings within the agglomeration of Łódź, Poland. The study related to adults. Material and Methods: As the research material, medical records of patients hospitalized due to an acute poisoning in the Department of Toxicology in Łódź were used. Information on the hospitalized patients was gathered in the database created in accordance with the assumed criteria and an approved system of the collection of variables describing the issues of intentional acute poisonings. Results: In the analyzed period, within the group of 18918 adult patients hospitalized due to an acute poisoning, male patients prevailed, accounting for $57.17 \%$ of the whole group. Intentional poisonings constituted $40.19 \%$ of all poisonings, with women dominating within that group of patients - accounting for approximately $58.63 \%$. The largest group was formed by young people, 18-35 years old, accounting for $43.22 \%$. The average age of the intentionally poisoned patients showed an upward tendency; this tendency concerned women to a larger extent. Medications played the most powerful role in acute intentional poisonings. Within the whole population, they were responsible for $97.27 \%$ of intoxications. The analysis of the dynamics of changes in the percentage of patients referred for further mental treatment revealed that the number of patients continuing hospital treatment in psychiatric wards tended to grow. Conclusions: Observations indicating that women are more likely to attempt intentional poisoning, and that the number of patients with psychiatric disturbances tended to grow in the analyzed period, demonstrate an urgent need for preventive measures to be taken in the local communities. Int J Occup Med Environ Health. 2020;33(1):77-90
\end{abstract}

Key words:

epidemiology, self-poisonings, suicidal attempt, toxicology, xenobiotics, retrospective study

\section{INTRODUCTION}

The scale of the problem associated with suicidal behaviors has been growing in recent years. According to the estimated data, in each year of the first decade of the 21st century, almost a million people worldwide, and approximately 150000 people in Europe, died as a consequence of a suicidal attempt [1]. At present, suicides account for $1.5 \%$ of all death cases, and appear in the 10th position among the main causes of death. Approximately $75 \%$ of these cases refer to low and medium income countries $[2,3]$.

\footnotetext{
Funding: this work was supported by the Nofer Institute of Occupational Medicine (grant No. 13.3, entitled "Identification and evaluation of toxic factors, kind and conditioning of acute poisonings on the basis of databases runing in the Poison Information Centre," grant manager: Anna Piekarska-Wijatkowska, Ph.D.)

Received: May 16, 2019. Accepted: October 21, 2019.

Corresponding author: Anna Piekarska-Wijatkowska, Nofer Institute of Occupational Medicine, Toxicology Clinic, Poison Information Centre, św. Teresy 8, 91-348 Łódź, Poland (e-mail: anna.piekarska@imp.lodz.pl).
} 
Assumingly, depending on the country, region or ethnic group, the number of attempts may correspond to 10 , or even 20, actually committed suicides [4]. The first WHO report on the prevention against suicides, published in 2014, indicated 2 methods for obtaining information on the regional or national rates of suicidal attempts. The first method is an outcome of a study carried out by means of standardized tools and research methods on representative populations. The second one focuses on the analysis of medical documentation in hospital wards [5]. Nevertheless, experts working on the report have observed certain limitations that affect the credibility of information acquired using either of these methods. According to the report, they both lack an integrated research approach in the analysis of the acquired data. More importantly, the gathered material may not reflect the scale of the problem in a given region. Furthermore, a reliable evaluation of the indicators based on the information included in hospital records depends on the compliance with the adopted arrangements:

- separating cases of suicidal attempts from the actually committed suicides and analyzing them as 2 individual categories,

- differentiating and recording cases of self-mutilation or self-harm, inflicted with a suicidal intention, from the ones where no suicidal factor was identified,

- describing adequately the method used in each suicidal attempt.

Acute poisonings frequently result in hospitalization and pose a major health problem. In many countries, a vast majority of acute poisonings among adult patients are cases of deliberate self-poisonings, mainly involving medications. The core of the problem is the intentional consumption of a substance in a dose exceeding the value that is recommended or commonly regarded as therapeutic. Such an act is targeted at bringing about specific effects through the actual or expected consequences of provoked symptoms [6]. Based on a definition formulated in such a way, and taking into account the existence (or its lack) of motives that accompany a given poisoning case, deliberate self-poisonings may be divided into 2 subgroups:

- intentional self-poisonings, where a suicidal nature was diagnosed and registered in medical records by the hospital staff,

- cases of overdosing, which represent self-destructive behaviors without a proved suicidal intention [7].

The intention behind the categories of self-poisonings as mentioned above, i.e., deliberate self-poisoning and overdose cases, translate into a kind, quantity and cooccurrence of consumed xenobiotics. This also refers to the risks that accompany self-poisonings. Importantly, it may also affect the treatment process, e.g., hospital discharge contrary to the doctor's recommendation or rehospitalization for the same cause.

Literature on suicidality in Poland offers few works dedicated to the problem, while the evidence of committed suicides is quite well documented. Similarly, hardly ever do scientific studies and publications deal with acute poisonings of a deliberate nature, which de facto is the case of suicidal attempts. Therefore, the aim of this study was to review the occurring changes and tendencies with respect to the frequency, circumstances and course of acute deliberate self-poisonings among adults residing in one of the agglomerations in Poland.

\section{MATERIAL AND METHODS}

Medical records of the patients hospitalized due to acute poisonings in the Toxicology Department of the Nofer Institute of Occupational Medicine (TD NIOM) in Łódź, Poland, over the period 2004-2013, constituted the research material. All the medical records of the years covered by the study underwent an analysis.

In order to carry out a standardized evaluation of the specificity and scale of the acute poisoning phenomenon among the examined population, the following qualification criteria were applied with reference to the patients hospitalized in the TD NIOM in Łódź: 
- an acute poisoning confirmed by medical records,

- residence within the agglomeration,

- age $\geq 18$ years.

The choice of the geographical criterion limiting the examined area to the agglomeration was affected by the longterm organizational and medical model in the local health care service. According to that model, all adult inhabitants of the agglomeration suspected of, or diagnosed with, an acute poisoning are referred to the TD NIOM in Łódź.

In 2004, the population of the Lódź agglomeration was 1148370 inhabitants, out of whom 961790 were adults. In the last year of the decade, a decrease in both the total number of inhabitants (1 100 208) and adults (932 722) was observed.

By studying the quality parameters of the analyzed patient population and the regularities observed within the whole examined group of patients hospitalized due to acute deliberate self-poisonings, structural indicators were calculated, exposing in particular the indexes per 10000 inhabitants. The calculations covered all the comparable demographic parameters provided by the statistics for the Lódź agglomeration over the period 2004-2013.

As per time variables, dynamic indicators of the constant and variable basis, as well as the geometric mean (GM), were applied. For the non-measurable features, the nonparametric $\chi^{2}$ test was used. The minimum level of statistical validity was set at $\mathrm{p}<0.05$.

The statistical analysis was performed using Statistica version 11PL software.

\section{Ethical approval}

For this type of (retrospective) studies, no formal consent is required.

\section{RESULTS}

Within the research period, 21803 patients with an acute poisoning underwent treatment in the TD NIOM in Łódź, out of whom $86.76 \%$ (18 918 patients) met the study quali- fication criteria. Deliberate self-poisonings in this group constituted 40.19\% (7605 persons). Forty-eight persons (23 females and 25 males) died as a consequence of a suicidal poisoning in the reference period. Upon separating the category of committed suicides, the population under analysis included 7557 patients.

The results of the study concerning the dynamics of undertaken suicidal attempts are compiled in Table 1. The index calculated per 10000 inhabitants of the Lódź agglomeration amounted to 9.83 in the first year of the analyzed decade, and kept decreasing in the subsequent 4 years to eventually reach its lowest level in 2008 (6.36). Over the whole decade, the index demonstrated a downward trend in the dynamics of the phenomenon, which was also reflected in the value of the calculated dynamics ratio and geometric mean. The decrease in the fixed basis indicator, with respect to the year 2004, amounted to $11.61 \%$. The annual average number of poisonings dropped by $1.36 \%$.

\section{Gender of the deliberately self-poisoned patients}

Women accounted for $58.63 \%$ of the deliberately selfpoisoned group (4431 persons), whilst $41.37 \%$ were men (3126 patients). The decrease in the ratio of poisonings among men by half, from nearly 10 (9.80) to 5.0, within the 5-year period (2004-2008), and its subsequent rise in the next 5 years, to the level slightly lower than that at the beginning of the analyzed period (8.22 in 2013), were noted. A similar regularity was observed amongst women over the period 2004-2007, with the ratio of poisonings amounting to 10.02 and 6.84, respectively. Starting with 2008 , the deliberate self-poisoning ratio was rising to eventually reach the level lower than in 2004, and equalling 9.04. The downward trend of self-poisonings was more obvious in the case of men than in the case of women.

\section{Age of the deliberately self-poisoned patients}

The most numerous group of persons treated due to a suicidal poisoning was formed by patients aged 26-35 
Table 1. Dynamics of deliberate self-poisonings among the patients treated in the Toxicology Department of the Nofer Institute of Occupational Medicine in Łódź, Poland, in 2004-2013 ( $\mathrm{N}=7557$, deaths excluded)

\begin{tabular}{lccccc}
\hline & Year & Poisonings & Structural index & Index of poisonings/ \\
{$[\mathrm{n}]$} & {$[\%]$} & & \multicolumn{2}{c}{$\begin{array}{c}\text { Indicators of the dynamics of the basis } \\
\text { [\%] }\end{array}$} \\
\hline 2004 & & & & constant $^{\mathrm{a}}$ & variable $^{\mathrm{b}, \mathrm{c}}$ \\
\hline 2005 & 945 & 12.50 & 9.83 & 100.00 & - \\
2006 & 890 & 11.78 & 9.27 & 94.1 & 94.31 \\
2007 & 692 & 9.16 & 7.23 & 73.55 & 77.98 \\
2008 & 621 & 8.22 & 6.51 & 66.21 & 90.01 \\
2009 & 606 & 8.02 & 6.36 & 64.76 & 97.82 \\
2010 & 681 & 9.01 & 7.17 & 72.93 & 112.61 \\
2011 & 800 & 10.59 & 8.47 & 86.20 & 118.20 \\
2012 & 782 & 10.35 & 8.31 & 84.55 & 98.08 \\
2013 & 730 & 9.66 & 7.79 & 79.24 & 93.72 \\
Total & 810 & 10.72 & 8.68 & 88.39 & 111.55 \\
\hline
\end{tabular}

a $2004=100 \%$.

${ }^{\mathrm{b}}$ Previous year $=100 \%$.

${ }^{\mathrm{c}}$ Geometric mean $=98.64 \%$.

$(22.88 \%)$. Every fourth man $(26.62 \%)$ and every fifth woman $(20.24 \%)$ belonged to this group. In total, young people, aged $18-35$, constituted $43.22 \%$ of the overall number of the deliberately self-poisoned persons, while individuals in an economically productive age (18-65) accounted for $94.61 \%$. Only the remaining $5.39 \%$ of the deliberately self-poisoned patients belonged to the elderly persons' group, aged $\geq 66$. The breakdown of poisoning frequency in individual age groups differed substantially for men and women. That was also confirmed in the applied $\chi^{2}$ test, which revealed a significant statistical relationship, $\mathrm{p}<0.001$ (Table 2).

Older age among the self-poisoned patients was on the rise due to the growing average age of the patients who underwent treatment for that reason in the agglomeration over the analyzed period (Figure 1). That is particularly striking with respect to the intentionally intoxicated women, whose average age in the second half of the analyzed decade was significantly higher in compari- son with its first half. Among the male patients, the coefficient of the age structure of the deliberately selfpoisoned patients, over the period of 2004-2013, rose to a considerably lesser extent than for the female patients. The average age of the men treated in 2009-2010 was the lowest in the whole population of the deliberately self-poisoned persons.

\section{Marital status of the deliberately self-poisoned patients}

The marital status of the patients with an acute deliberate self-poisoning was documented in the analyzed source material of the TD NIOM in $96.3 \%$ of the cases. The structure of the patient population with acute deliberate poisonings according to the marital status was presented in Figure 2. The patients with no life partner constituted $58.10 \%$ (56.15\% - single women and $60.84 \%$ single men, respectively). Four out of 10 women (41.01\%) were married, and approximately every third man had a wife $(34.13 \%)$. 
Table 2. Frequency of deliberate self-poisonings among the patients treated in the Toxicology Department of the Nofer Institute of Occupational Medicine in Łódź, Poland, in 2004-2013, by gender and age group

\begin{tabular}{lccc}
\hline & & $\begin{array}{l}\text { Participants } \\
(\mathrm{N}=7557) \\
{[\mathrm{n}(\%)]}\end{array}$ & \\
\cline { 2 - 4 } & Age & $\begin{array}{c}\text { women } \\
(\mathrm{N}=4431)\end{array}$ & men \\
& total & $909(20.51)$ & $628(20.09)$ \\
\hline $18-25$ years & $1537(20.34)$ & $897(22.24)$ & $832(26.62)$ \\
$26-35$ years & $1729(22.88)$ & $836(18.87)$ & $655(20.95)$ \\
$36-45$ years & $1491(19.73)$ & $981(22.14)$ & $628(20.09)$ \\
$46-55$ years & $1609(21.29)$ & $499(11.26)$ & $285(9.12)$ \\
$56-65$ years & $784(10.37)$ & $168(3.79)$ & $60(1.92)$ \\
$66-75$ years & $228(3.02)$ & $141(3.18)$ & $38(1.22)$ \\
\hline 75 years & $179(2.37)$ & & \\
\hline
\end{tabular}

Chi $^{2}$ test $=99.69 ; \mathrm{p}<0.001$.

The analysis and dynamics of the marital status changes of the deliberately self-poisoned patients who were treated in the TD NIOM in 2004-2013 showed that, for the men and women alike, the number of deliberate self-poisoning cases decreased for the married patients, whilst it rose among the persons who remained single.

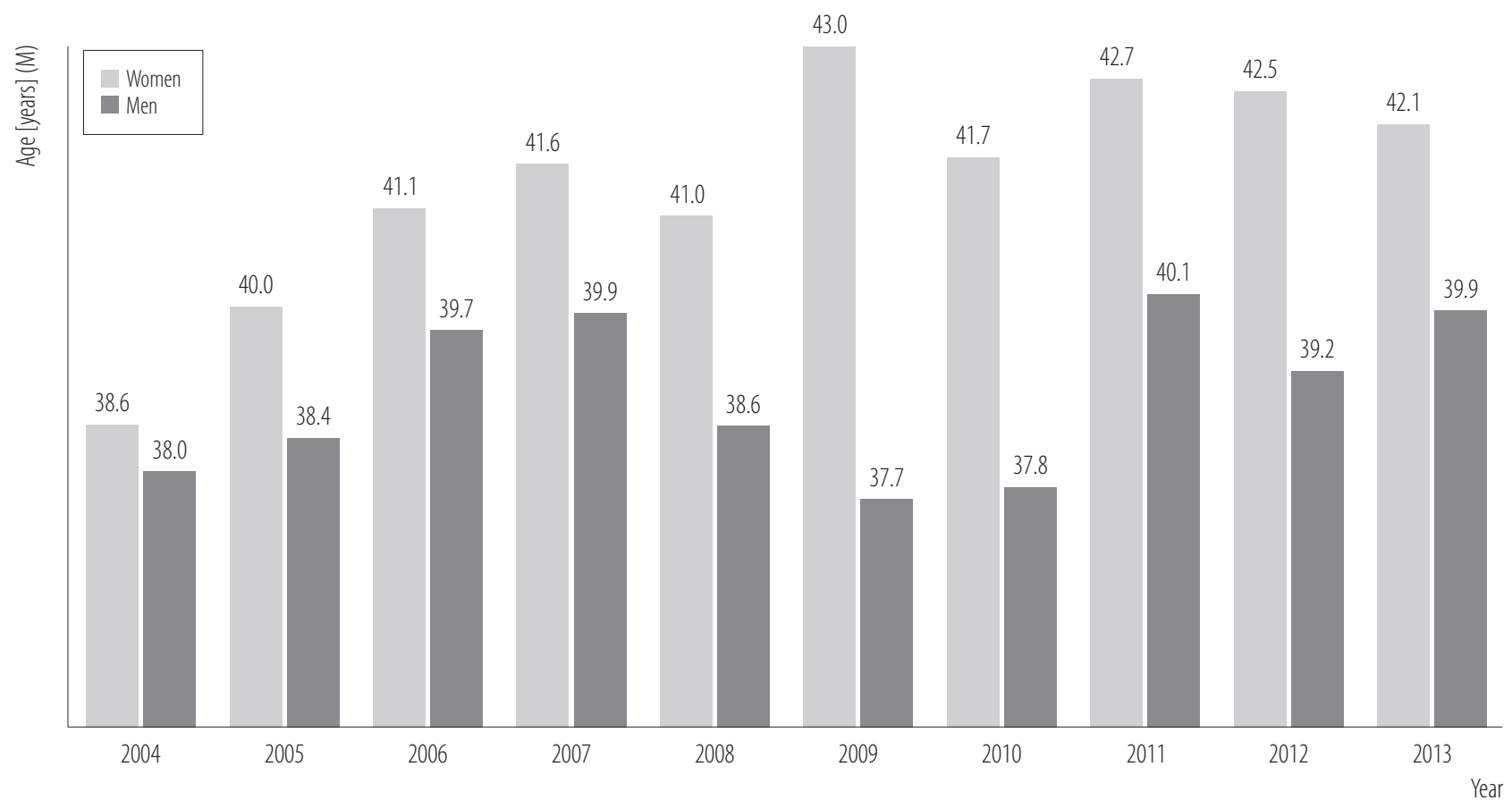

Figure 1. Age of the deliberately self-poisoned persons $(\mathrm{N}=7557)$ treated in the Toxicology Department of the Nofer Institute of Occupational Medicine in Łódź, Poland, in 2004-2013 


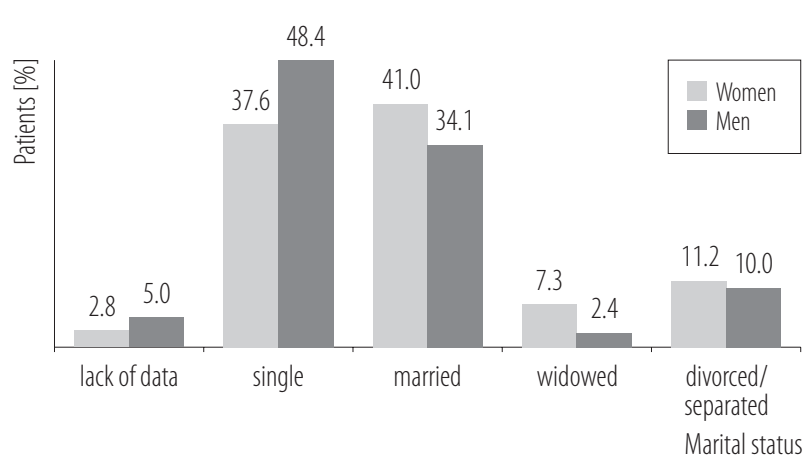

Figure 2. Marital status of the deliberately self-poisoned patients $(\mathrm{N}=7557)$ treated in the Toxicology Department of the Nofer Institute of Occupational Medicine in Łódź, Poland, in 2004-2013

\section{Place and time of self-poisonings}

In the case of $94.11 \%$ of the hospitalized patients (7112 persons in total, including $95.69 \%$ of women and $91.87 \%$ of men), self-poisonings occurred in their places of residence. One hundred and one patients (1.34\%) undertook a suicidal attempt when staying at a facility referred to as "a guest house." Two hundred and forty two persons (3.2\%), including 83 women (1.87\%) and 159 men (5.09\%), attempted a self-poisoning in public places, such as schools, outpatient clinics, hotels or streets. Locations such as parks, forests or garden plots were chosen for self-poisonings by 13 people $(0.17 \%)-5$ women $(0.11 \%)$ and 8 men $(0.26 \%)$, respectively. It is also worth noting that an acute self-poisoning of 41 people $(0.54 \%)$ happened during their stay in a hospital.

The season of the year and its respective characteristics that might affect, especially mentally, the performance of people, such as their well-being, mood or susceptibility to depression, may also provoke committing acts of self-aggression and suicidal attempts, including deliberate self-poisonings.

The downward trend of self-poisoning frequency in the annual comparison between the first and the second half of the year is demonstrated in Figure 3. Within the male population, the average poisoning frequency in the first half of the year amounted to $8.68 \%$, whilst in its second half to $7.99 \%$, and for the women to $8.53 \%$ in the first and to $8.14 \%$ in the second half of the year, respectively. In individual months of the year, the decreasing trend broke down similarly for each gender. All in all, the highest number of deliberate poisonings took place in January 698 persons, accounting for $9.24 \%$ of all the deliberate poisoning cases over the research period. The lowest number of patients were admitted in October -583 persons $(7.71 \%)$. January proved to be the month with the highest frequency of deliberate self-poisonings for men, while in the case of women it was May. The fewest women undertook suicidal attempts in October, and the same concerned men in August.

\section{Toxic factors responsible for poisoning}

Medications played the most powerful role in acute intentional poisonings. Within the whole population, they were responsible for $97.27 \%$ of intoxications (for $98.52 \%$ in the case of women and $95.49 \%$ in the case of men). Other toxic substances were the cause of poisonings for $1.48 \%$ of the women and $4.51 \%$ of the men within the whole intentionally intoxicated population. The group of patients poisoned with substances other than medications comprised 206 persons, including 65 women $(31.55 \%)$ and 141 men $(68.45 \%)$. Pesticides were responsible for the majority of deliberate self-poisonings among the men: 43 persons $1.38 \%$, and only in 15 women $(0.34 \%)$. Among the men, alcohol intoxication referred to 29 cases $(0.93 \%)$, while only 5 such cases were found among the women $(0.11 \%)$. In the alcohol intoxicated group of patients, cumulatively for both genders, in 18 cases the main factor was ethylene glycol; 12 persons got intoxicated with ethanol; methanol was responsible for 3 other cases, while one person chose isopropanol. The highest proportion of women within the group of non-drug poisonings used caustic substances $0.56 \%$, namely 25 persons. The same xenobiotic was used by 19 men $(0.61 \%)$. Chemical solvents constituted another 


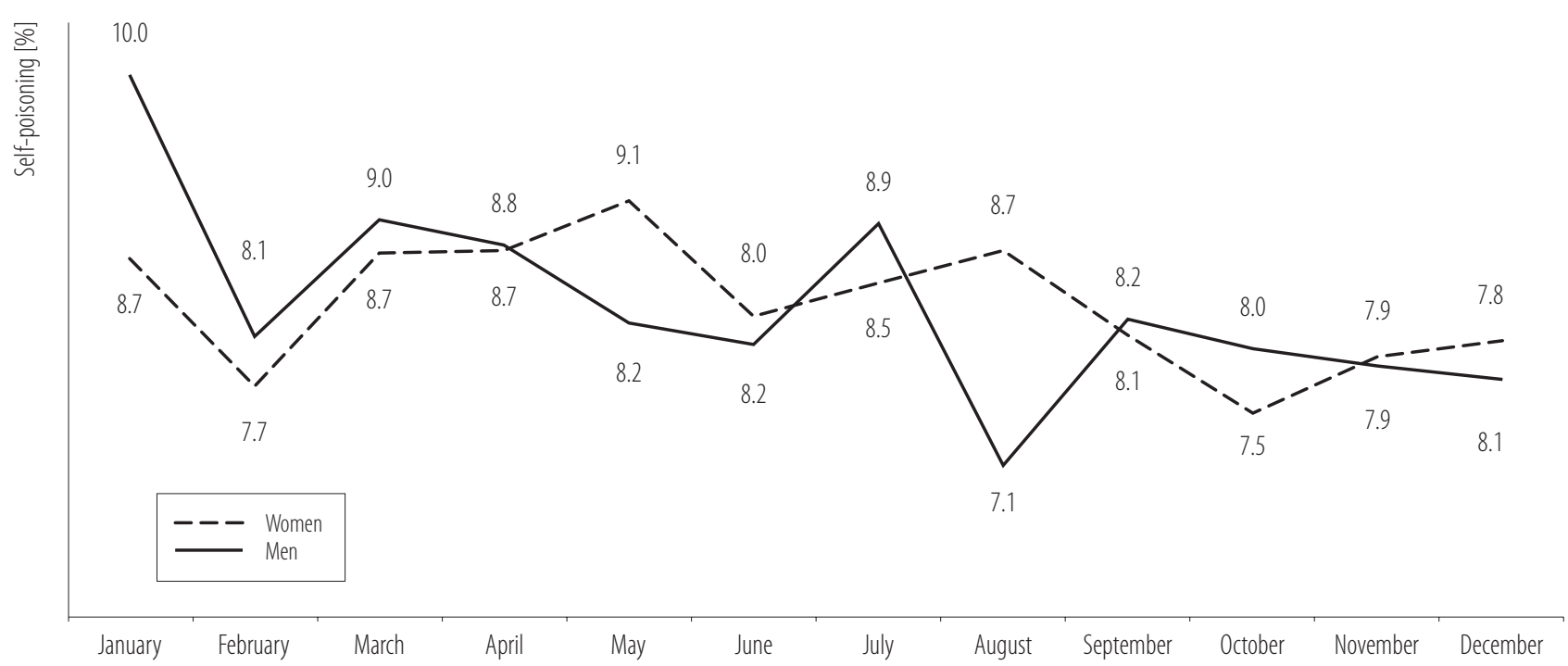

Figure 3. Frequency of deliberate self-poisonings in individual months $(\mathrm{N}=7557)$ among the patients treated in the Toxicology Department of the Nofer Institute of Occupational Medicine in Łódź, Poland, in 2004-2013

group of intoxicating agents, selected by 15 men $(0.48 \%)$ and 6 women $(0.14 \%)$, followed by narcotics and psychoactive substances (16 men, $0.51 \%$; 4 women, $0.09 \%$ ), and gases (10 men, $0.32 \%$; 3 women, $0.07 \%$ ).

\section{Toxic factors accompanying poisonings}

Forty-nine point forty nine percent of the deliberate poisoning acts were committed with 1 toxicant. The presence of alcohol as an additional factor was confirmed in the case of $49.23 \%$ of the patients. Only 97 persons $(1.28 \%)$ out of the overall number got intoxicated with an accompanying agent other than alcohol. Half of them (48 persons, $0.64 \%$ ) were patients who chose a narcotic or other stupefacient as an additional agent. Medicaments as an accompanying agent were identified in 31 cases $(0.41 \%)$. They concerned incidents where the main intoxicating factor was a substance other than drugs. Irritants and caustic substances, as an accompanying factor, were selected by 4 people, mushrooms or pesticides were used by $5(0.06 \%)$ or $3(0.03 \%)$ persons, respectively; additionally, a single case of poisoning with mercury was confirmed in the case of 1 person.

\section{Termination of hospitalization -}

\section{the final treatment outcome}

Approximately every tenth patient (10.60\% of the female patients and $12.47 \%$ of the male patients), following an intentional poisoning and fundamental recovery, would leave the TD in a good shape, without recommendations. Every fifth person $(19.58 \%$ of the men and $19.82 \%$ of the women) got discharged at their own request. About $11 \%$ of the discharged male patients $(10.83 \%$ ) and $9.25 \%$ of the female patients left with a recommendation of further treatment in an outpatient clinic or a specialist hospital. The proportion of patients after intentional poisonings referred to mental health outpatient clinics amounted to $14.44 \%$ of the men and to $23.01 \%$ of the women, respectively. Zero point twenty two percent of the men and $0.27 \%$ of the women were referred to the Municipal Addiction Prevention and Therapy Centre. Deceased cases constituted $0.52 \%$ among the women and $0.79 \%$ among the men. The largest group of patients was transferred to psychiatric hospitals to continue treatment (41.67\% of the men and $36.53 \%$ of the women). All in all, approximately 6 out of 10 patients were referred to a specialist 
psychiatric institution $(56.11 \%$ of the men and $59.54 \%$ of the women).

The analysis of the dynamics of changes in the percentage of patients referred for further mental treatment revealed that the number of patients continuing hospital treatment in psychiatric wards tended to grow. In the first year, the proportion equaled $36.73 \%$ for the men and $23.71 \%$ for the women. In 2012 and 2013, this percentage increased to reach $61.13 \%$ and $53.45 \%$ for the men, $59.67 \%$ and $46.75 \%$ for the women, respectively. At the same time, a decrease in the percentage of patients referred to psychiatric outpatient clinics was observed. The proportion of referrals among the women dropped from $24.86 \%$ in 2004 to $17.53 \%$ in 2013, while for the men from $15.17 \%$ in the first year of the decade to $10.06 \%$ in its last year.

\section{DISCUSSION}

Self-poisoning - a conscious action consisting in taking toxic substances - which is aimed at achieving an immediate, expected outcome. Regardless of the effect, suicidal behaviors constitute an indicator of social maladjustment, as initiating self-destructive actions is viewed as a symptom of alienation from one's family, social or professional background, etc. [8-10].

The data compiled in the patients' records in the TD NIOM, referring to the circumstances of suicidal attempts through self-intoxication, enabled tracking the dynamics of changes in the number of intentionally inflicted acute poisonings over a decade. The number of patients, in both absolute numbers and calculated coefficients, decreased. Similarly, the rate of intentional intoxications lowered per 10000 inhabitants of the Lódź agglomeration, which in the first year of the research reached 9.83, whilst in its last year (2013) dropped to 8.68.

In Poland, a comparison of the data presented above faces serious difficulties due to the shortage of scientific publications dealing with the problem. Publications related to this topic, released at the beginning of the 21st century and referring to the inhabitants of Kraków and its surroundings, either dealt exclusively with the oldest population group [11] or embraced adolescents as well as adults [12]. In the study of 2000-2002, there was an increase in the number of hospitalizations resulting from suicidal attempts in the second year and a slight decrease in the last year of the study [12].

In foreign literature, there exist documented data concerning suicidal attempts but presenting the phenomenon from different angles.

The rise in the frequency of suicidal attempts by $35 \%$, and of all poisonings cumulatively (by 34\%), was observed at the subsequent stages of the problem in the analysis carried out in Spain, under the title "VEIA 2004" [13]. Its goal was to record and evaluate all cases of acute poisonings among adults reporting to the hospital emergency ward in Madrid.

A research initiative by German toxicologists covering an 8-year period of 2005-2012, implemented in Leipzig, seems to have similar results and the time scope to a decade-long study period as presented in this publication. The aim of the analysis was to assess the frequency of acute poisonings among adult citizens. The outcome revealed that although the overall number of poisonings had doubled, the frequency of undertaken suicidal attempts remained at the same level [14].

Gender is one of the major demographic factors affecting self-destructive behaviors. In numerous places worldwide, male suicides lose life more frequently, while women dominate in the group where acts of suicide do not end in death. The phenomenon called the "paradox of gender in suicidal behaviors" seems to confirm the trend to adopt patterns of behavior leading to self-destruction, which primarily result from cultural conditions and roles played in the society [15]. The above mentioned disproportions have been confirmed in the course of analyses carried out in the USA and Spain $[16,17]$, as well as in the Suicide Trends in At-Risk Territories (START) study by WHO. Originally, it was supposed 
to cover the area of Western Pacific, but it was ultimately extended to other regions of the globe. The results obtained in the centers participating in the START program have demonstrated the domination of women among persons undertaking suicidal attempts, with the exception of the Philippines where men constituted a more numerous group of $62.4 \%$ [18].

Among the inhabitants of the Lódź agglomeration hospitalized in the TD NIOM due to a deliberate self-poisoning in all the analyzed years, female patients prevailed, their approximate share being $58.63 \%$. A very similar share of women $(58.3 \%)$ was revealed by the study carried out in Kraków, which focused on analyzing the frequency with which self-poisoning attempts were undertaken with respect to gender and age [12]. In the comparative breakdown of data on the deliberate self-poisonings in Oxford (England) and Newcastle (Australia), the percentage share of women within the whole group of suicides was even higher, with $63.7 \%$ and $62.3 \%$, respectively [19], and in Melbourne $-64.6 \%$ [20]. The share of women in the deliberately self-poisoned group of patients, reaching nearly $70 \%$, was also observed in Mumbai (India), in the same study where in the overall number of poisoned persons men proved to constitute the majority [21]. A similar situation was noted in the population of the poisoned patients in Palestine [22].

Also in individual age groups, into which the population of the deliberately poisoned adults residing in the Łódź agglomeration of Łódź was broken down, women were more numerous. At the same time, young persons constituted the biggest group: $18-35$ years old patients $-43.22 \%$, while older patients, aged $>65$, accounted for only $5.39 \%$.

The fact that self-poisoning acts are committed most often by young patients has been confirmed in the recently published reports on acute poisonings [20,23,24]. A different outcome was obtained in the study by Bjornaas et al. [25], as the inhabitants of Oslo hospitalized as a consequence of suicidal attempts were mostly aged $30-49$, this group con- stituting 52\% of the cases. Younger patients, aged 16-29, participated in the mere $27 \%$ of undertaken attempts.

It is worth noting that in the analysis concerning deliberate self-poisonings within the Łódź agglomeration, the rate of poisonings per 10000 inhabitants for the older age groups of $\geq 56-65$ demonstrated an upward trend. Moreover, the average age of the deliberately self-poisoned patients tended to grow; that trend referred, to a larger extent, to women. As stressed by the researchers dealing with that aspect of the problem, suicides attempted by self-intoxication, undertaken in the second half of one's life, bear significant consequences on the social, economic and personal scale, and above all pose a great risk to further life and health of the persons undertaking them [11].

An important factor, underlying behaviors that may result in acute poisoning, is the character of social support provided by the closest surroundings and family. Many authors emphasize how vital the lack of properly shaped, strong social bonds and family relations may prove for the occurrence of self-destructive inclinations $[9,25,26]$. The majority of the latest reports seem to confirm that people leading lonely lives significantly more frequently choose to undertake a suicidal attempt than those living in matrimony or partnership $[19,20,25,27]$. The results obtained in the analysis performed as part of this work are consistent with the conclusions presented above; $56.15 \%$ of the women and $60.84 \%$ of the men hospitalized in the TD NIOM following a deliberate self-poisoning did not have a life partner. Monitoring that trend over the decade confirmed a continuous escalation of the problem as the proportion of single persons in the population of either gender was systematically increasing.

The influence of external factors, such as seasons of the year and respective weather unsteadiness, on committing acts of self-aggression is reflected in the seasonal nature of suicidal attempts. The corresponding literature provides results of a study on this aspect of the problem with respect to days of 
the week, individual months or cyclically occurring festive days such as Christmas or the New Year's Day.

Some results of the analysis devoted to the seasonality of suicidal attempts, presented in monthly terms, seem to prove a higher frequency of attempts in May, as well as in the first months of the summer - June and July [28]. Some researchers, however, take a different stance. Mergl et al. [29], in the study carried out in North Bavaria, showed that in spring the rate of suicidal attempts among women was the lowest, while for men it did not differ substantially from month to month.

In Łódź and its surroundings, the adult female inhabitants tended to attempt suicide the most frequently in May and the least often in October. Among the men, the lowest number of attempts occurred in August. Nonetheless, it needs to be stressed that differences in the frequency of poisonings in particular months were not statistically significant for either the women or the men.

The use of xenobiotics as a means to accomplish the goal of committing suicide is conditioned by their availability. It may be additionally motivated by the common stereotypical knowledge on how the substances may affect the body. In the majority of European countries, suicidal attempts are undertaken with drugs, and the proportion of so deliberately self-poisoned persons constitutes at least $5 \%$ of all patients hospitalized per year [30-32].

Apart from drug poisonings, growing anxiety concerns the number of accidental intoxications, above all deliberate, with pesticides as the main toxic factor. According to WHO, half of the intoxications with this factor involved takes place in developing countries, even though their share in the global production of pesticides merely equals $15 \%$ [33]. A relatively easy access, a low level of knowledge concerning poisoning risks, and above all high toxicity of preparations used in Asia, Africa and many other regions are the reasons for a number of self-harm cases which are still hard to estimate. Sri Lanka is a country with a high ratio of deliberate poisonings mainly with pesticides, but also with plants of the Nerium kind or drugs. Numerous publications have been dedicated to documenting that long-term problem [34-37]. As emphasized in the latest works, changes in the field of epidemiology of deliberate self-poisonings observed in those regions of the world may be compared to the patterns existing in industrialized countries: persons undertaking suicidal attempts declare their choice of xenobiotics as based on their availability. Among women, drugs were the most common factor, while men having chemical substances within their reach chose pesticides more frequently [38].

In China, the number of intoxications with pesticides tends to grow; the latest findings also indicate that the frequency of poisonings with this factor, specifically for the region, depends on age [39]. In the younger age group (women aged 20-59, men aged 20-69), pesticide intoxications were found to dominate: $89 \%$ and $85 \%$, respectively, whereas among senior citizens deliberate self-poisonings with drugs proved the most common (81\% and 70\%). Furthermore, more deliberate self-poisonings with pesticides occurred in typically farmed areas of China.

Despite a decrease in the number of deaths caused by poisonings with pesticides containing aluminium phosphide, or belonging to the group of carbamates and organophosphorus compounds, the country where acute poisonings with pesticides still appear a burning issue is India [40,41]. The same groups: organophosphorus pesticides and carbamates, as well as derivatives of warfarin were responsible for most cases of deliberate self-poisonings in Zimbabwe. Intoxications with pesticides are a frequent reason for hospitalization owing to the fact that agriculture constitutes the basis for living for most citizens of that country, and both the storage and sales of such products are not adequately supervised [42].

In the Łódź agglomeration, poisonings with pesticides as the main toxic factor constituted a minor percentage: $0.34 \%$ for the women and $1.38 \%$ for the men, which in turn results from a typically urban lifestyle of the analyzed 
population. Deliberate self-poisonings with other toxic factors also referred to small groups of the hospitalized patients: corrosives $0.56 \%$ and $0.61 \%$ for the women and men, respectively, and alcohol $0.93 \%$ for the men and only $0.11 \%$ for the women. Meanwhile, alcohol as a factor accompanying self-poisoning was identified with nearly half of the patients $(49.23 \%)$. Over the analyzed period, the frequency of alcohol co-occurrence in the deliberate self-intoxications increased by $10 \%$.

Suokas and Lönnqvist [43], in the study focusing on the inhabitants of Helsinki hospitalized due to suicidal attempts by self-poisonings, indicated that $62 \%$ of these persons consumed alcohol before or during the act of self-destruction. In American surveys, the increase in alcohol co-occurrence in self-poisonings was observed among young people (aged 18-24), from 14\% in 1999 to $20 \%$ in 2008, along with a significant increase among older people, in the $>70$ age group, in the analysis period of 2005-2010 [44,45]. As emphasized by the authors, the interaction between alcohol and the dose of drugs taken with the aim of self-destruction may pose a serious hazard for a person's life, especially in the case of elderly suicides [45,46].

For reasons beyond the authors' control, no data on the number of suicidal attempts undertaken by the patients in the past could be collected in this work. However, a growing threat that affects the future is evidenced by a high percentage of people who, after the end of treatment in the TD NIOM, were referred for further mental health therapy. The need was found among almost 6 out of 10 patients, accounting for $56.11 \%$ of the men and $59.54 \%$ of the women. In the analyzed years, the increase in the frequency of referrals to hospital psychiatric wards was noted, especially in 2012 (60.40\%) and 2013 (50.10\%). These percentages appear to be much higher in comparison with the latest data gathered from the available studies. Among Oslo residents hospitalized due to intentional poisonings, $38 \%$ of patients continued treatment in psychiatric wards [25], in Newcastle (Australia) this con- cerned $28 \%$ of patients, and an even lower percentage of patients referred to psychiatric wards was reported in Oxford $-8 \%$ [19].

The authors of this study are aware of the fact that the time range of the analyzed data, ending in 2013, may be critically assessed. However, they hope that the presented results will be helpful in solving the important and growing problem of an acute intentional poisoning.

\section{CONCLUSIONS}

In summary, this is the first study comprehensively examining the problem of acute intentional poisonings among the adult population of Łódź, Poland. The observations that women are more likely to attempt an intentional poisoning, and that the number of patients with psychiatric disturbances tended to grow in the analyzed period, demonstrate the need for preventive measures in the local communities. It is also important to obtain precise information on the agents encountered in an intentional poisoning in future projects.

\section{REFERENCES}

1. World Health Organization [Internet]. Geneva: The Organization; 2015 [cited 2015 Sep 18]. Suicide date. Available from: http://www.who.int/mental_health/suicide-prevention/en/.

2. Levi F, La Vecchia C, Lucchini F, Negri E, Saxena S, Maulik PK, et al. Trends in mortality from suicide, 1965-99. Acta Psychiatr Scand. 2003;1008:341-9, https://doi.org/10.1034/j. 1600-0447.2003.00147.x.

3. Hawton K, van Heeringen K. Suicide. Lancet. 2009;373:137281, https://doi.org/10.1016/S0140-6736(09)60372-X.

4. Fleischmann A, Bertolote JM. Suicidal behavior in a global health perspective. Int J Ment Health. 2003;32:67-78, https:// doi.org/10.1080/00207411.2003.11449580.

5. World Health Organization [Internet]. Geneva: The Organization; 2014 [cited 2015 Sep 19]. Preventing suicide. A global imperative. Available from: http://www.who.int/mental_ health/suicide-prevention/world_report_2014/en/. 
6. Kerkhof AJFM. Attempted suicide: Patterns and trends. In: Hawton K, van Heeringen K, editors. The International Handbook of Suicide and Attempted Suicide, Chichester (UK): Wiley; 2000 [cited 2015 Sep 19]. p. 49-64. Available from: https://doi.org/10.1002/9780470698976.ch3.

7. Camidge DR, Wood RJ, Bateman DN. The epidemiology of self-poisoning in the UK. Br J Clin Pharmacol. 2003;56:6139, https://doi.org/10.1046/j.1365-2125.2003.01910.x.

8. Jarosz M. [Suicides]. Warszawa: PWN; 1997. Polish.

9. Gmitrowicz A. [Social and psychiatric determinants of attempted suicide in youth]. Postęp Psychiatr Neurolog. 1999;8(4):457-64 [cited 2015 Sep 19]. Available from: http:// old.ipin.edu.pl/ppn/archiwum/pliki/1999/04/PPiN_4-199908.pdf. Polish.

10. Polewka A, Groszek B, Trela F, Zięba A, Bolechała F, Chrostek-Maj J, et al. [The completed and attempted suicides in Kraków - similarities and differences]. Prz Lek. 2002;59(4-5):298-303. Polish.

11. Polewka A, Kroch S, Chrostek-Maj J, Pach J, Zięba A. [Suicide attempts by self-poisoning among the elderly]. Prz Lek. 2002;59(4-5):291-4. Polish.

12. Polewka A, Groszek B, Targosz D, Szkolnicka B, ChrostekMaj J, Kroch S, et al. [The frequency of suicide attempts depending on gender and the age structure]. PrzLek. 2004;61(4): 265-8. Polish.

13. Caballero Vallés PJ, Dorado Pombo S, Díaz Brasero A, García Gil ME, Yubero Salgado L, Torres Pacho N, et al. [Epidemiologic survey of acute poisoning in the south area of the community of Madrid: the VEIA 2004 study]. An Med Interna. 2008;25(6):262-8 [cited 2015 Sep 19]. Available from: http:// scielo.isciii.es/scielo.php?script $=$ sci_arttext\&pid $=$ S0212$71992008000600003 \& \operatorname{lng}=$ en\&nrm=iso. Spanish.

14. Sorge M, Weidhase L, Bernhard M, Gries A, Petros S. Selfpoisoning in the acute care medicine 2005-2012. Anaesthesist. 2015;64:456-62, https://doi.org/10.1007/s00101-015-0030-x.

15. Canetto SS, Sakinofsky I. The gender paradox in suicide. Suicide Life-Threat Behav. 1998;28(1):1-23, https://doi.org/ 10.1111/j.1943-278X.1998.tb00622.x.
16. Iribarren C, Sidney S, Jacobs DR Jr, Weisner C. Hospitalization for suicide attempt and completed suicide: epidemiological features in managed care population. Soc Psychiatry Psychiatr Epidemiol. 2000;35:288-96, https://doi.org/ 10.1007/s001270050241.

17. Alberdi-Sudupe J, Pita-Fernandez S, Gomez-Pardiñas SM, Iglesias-Gil-de-Bernabe F, Garcia-Fernandez J, MartinezSande G, et al. Suicide attempts and related factors in patients admitted to a general hospital: a ten-year crosssectional study (1997-2007). BMC Psychiatry. 2011;11(51): 1-10, https://doi.org/10.1186/1471-244X-11-51.

18. De Leo D, Milner A, Fleischmann A, Bertolote J, Collings S, Amadeo S, et al. The WHO START study. Suicidal behaviors across different areas of the world. Crisis. 2013;34(3):15663, https://doi.org/10.1027/0227-5910/a000193.

19. Hiles S, Bergen H, Hawton K, Lewin T, Whyte I, Carter G. General hospital-treated self-poisoning in England and Australia: comparison of presentation rates, clinical characteristics and aftercare based on sentinel unit data. J Psychosomat Res. 2015;78:356-72, https://doi.org/10.1016/j.jpsychores. 2015.01.006.

20. Rahman A, Martin C, Graudins A, Chapman R. Deliberate self-poisoning presenting to an emergency medicine network in south-east Melbourne: a descriptive study. Emerg Med Int. 2014:1-7, https://doi.org/10.1155/2014/461841.

21. Patil A, Peddawad R, Verma VCS, Gadhi H. Profile of acute poisoning cases treated in a tertiary care hospital: a study in Navi Mumbaj. Asia Pac J Med Toxicol. 2014;3:36-40, https:// doi.org/10.22038/apjmt.2014.2469.

22. Sawalha AF, Sweileh WM, Tufaha MT, Al-Jabi DY. Analysis of the pattern of acute poisoning in patients admitted to a governmental hospital in Palestine. Basic Clin Pharmacol Toxicol. 2010;107:914-8, https://doi.org/10.1111/j.17427843.2010.00601.x.

23. Prescot K, Stratton R, Freyer A, Hall I, Le Jeune I. Detailed analyses of self-poisoning episodes presenting to a large regional teaching hospital in the UK. Br J Clin Pharmacol. 2009;68(2): 260-8, https://doi.org/10.1111/j.1365-2125.2009.03458.x. 
24. Lund C, Vallersners OM, Jacobsen D, Ekeberg O, Hovda KE. Outpatient treatment of acute poisonings in Oslo: poisoning pattern, factors associated with hospitalization, and mortality. Scand J Trauma Resusc Emerg Med. 2012;20(1):1-10, https://doi.org/10.1186/1757-7241-20-1.

25. Bjornaas MA, Hovda KE, Heyerdahl F, Skog K, Opdahl A, Jacobsen D, et al. Suicidal intention, psychosocial factors and referral to further treatment: a one-year cross-sectional study of self-poisoning. BMC Psychiatry. 2010;10(58):1-11, https://doi.org/10.1186/1471-244X-10-58.

26. Duberstein PR, Conwell Y, Conner CR, Eberly S, Evinger JS, Caine DE. Poor social integration and suicide: fact or artifact? A case-control study. Psycholog Med. 2004;34(7): 1331-7, https://doi.org/10.1017/S0033291704002600.

27. Dedić G, Djurdjević S, Golubović B. Psychological assessment of persons following suicide attempt by self-poisoning. Vojnosanit Pregl. 2010;67(2):151-8, https://doi.org/10.2298/ VSP1002151D.

28. Polewka A, Kopciuch M. [Seasonality and periodic fluctuations of suicide attempts]. Suicidology. 2006;2:88-94. Polish.

29. Mergl R, Havers I, Althaus D, Rihmer Z, Schmidtke A, Lehfeld $\mathrm{H}$, et al. Seasonality of suicide attempts: association with gender. Eur Arch Psychiatry Clin Neurosci. 2010;260: 393-400, https://doi.org/10.1007/s00406-009-0086-1.

30. Camidge DR, Wood RJ, Bateman DN. The epidemiology of self-poisoning in the UK. Br J Clin Pharmacol. 2003;56: 613-9, https://doi.org/10.1046/j.1365-2125.2003.01910.x.

31. Michel K, Ballinari P, Bille-Brahe U, Bjerke T, Crepet P, De Leo D, et al. Methods used for parasuicide: results of the WHO/EURO Multicentre Study on Parasuicide. Soc Psychiatry Psychiatr Epidemiol. 2000;35:156-63, https://doi. org/10.1007/s001270050198.

32. Carter GL, Clover K, Whyte IM, Dawson AH, D'Este C. Postcard from the EDge project: randomised controlled trial of an intervention using postcards to reduce repetition of hospital treated deliberate self-poisoning. BMJ 2005;331:805-7, https://doi.org/10.1136/bmj.38579.455266.E0.
33. World Health Organization, International Programme on Chemical Safety. Epidemiology of pesticide poisoning: harmonized collection of data on human pesticide exposure in selected countries. Geneva: WHO Press; 2004.

34. Eddleston M, Philips MR. Self poisoning with pesticides. Br Med J. 2004;328:42-4, https://doi.org/10.1136\%2Fbmj. 328.7430 .42 .

35. Eddleston M. Choice of poison for intentional self-poisoning in rural Sri Lanka. Clin Toxicol. 2006;44:283-6, https:// doi.org/10.1080/15563650600584444.

36. Rajapakse T, Griffiths KM, Christensen H. Characteristics of non-fatal self-poisoning in Sri Lanka: a systemic review. BMC Pub Health. 2013;13(331):1-15, https://doi. org/10.1186/1471-2458-13-331.

37. Senarathna L, Jayamanna SF, Kelly PJ, Buckley NA, Dibley M, Dawson AH. Changing epidemiologic patterns of deliberate self poisoning in a rural district of Sri Lanka. BMC Pub Health. 2012;12(593):1-8, https://doi.org/10.1186/14712458-12-593.

38. Rajapakse T, Griffiths K, Christensen H, Cotton S. A comparison of non-fatal self-poisoning among males and females in Sri Lanka. BMC Psychiatry. 2014;14(221):1-22, https:// doi.org/10.1186/s12888-014-0221-z.

39. Zhang J, Xiang P, Zhuo X, Shen M. Acute poisoning types and prevalence in Shanghai, China, from January 2010 to August 2011. J Foren Sci. 2014;59(2):441-6, https://doi. org/10.1111/1556-4029.12334.

40. Murali R, Bhalla A, Singh D, Singh S. Acute pesticide poisoning: 15 years experience of a large North-West Indian hospital. Clin Toxicol. 2009;47:35-8, https://doi.org/ 10.1080/15563650701885807.

41. Banerjee I, Tripathi SK, Roy AS. Clinico-epidemiological profile of poisoned patients in emergency department: a two and half years's single hospital experience. Int $\mathrm{J}$ Crit Illn Inj Sci. 2014;4(1):14-7, https://doi.org/10.4103\% 2F2229-5151.128007.

42. Tagwireyi D, Ball DE, Nhachi CFB. Toxicoepidemiology in Zimbabwe: pesticide poisoning admissions to major 
hospitals. Clin Toxicol. 2006;44:59-66, https://doi.org/10.1080/ 15563650500394878.

43. Suokas J, Lönnqvist J. Suicide attepmts in which alcohol is involved: a special group in general hospital emergency rooms. Acta Psychiatr Scand. 1995;91:36-40, https://doi. org/10.1111/j.1600-0447.1995.tb09739.x.

44. White AM, MacInnes E, Hingson R, Pan I-J. Hospitalization for suicide-related drug poisonings and co-occuring alcohol overdoses in adolescents (ages 12-17) and young adults (ages 18-24) in the United States, 1999-2008: results from the Nationwide Inpatient Sample. Suicide Life-Threat Behav. 2013;43(2):198-212, https://doi.org/10.1111/sltb.12008.

45. Conner KR, Huguet N, Caetano R, Giesbrecht N, McFarland $\mathrm{BH}$, Nolte KB, et al. Acute use of alcohol and methods of suicide in a US National Sample. Am J Public Health. 2014;104(1):171-8, https://doi.org/10.2105/AJPH.2013.301352.

46. Moore AA, Whiteman EJ, Ward KT. Risks of combined alcohol/medication use in older adults. Am J Geriatr Pharmacother. 2007;5(1):64-74, https://doi.org/10.1016/j.amjopharm.2007.03.006.

This work is available in Open Access model and licensed under a Creative Commons Attribution-NonCommercial 3.0 Poland License - http://creativecommons.org/ licenses/by-nc/3.0/pl/deed.en. 